Ana Cláudia Barbosa da Silva ${ }^{1}$

Milton Athayde ${ }^{2}$

\section{O Programa de Saúde da Família sob o ponto de vista da atividade: uma análise das relações entre os pro- cessos de trabalho, saúde e subjetivação*}

\author{
The Family Health Program from the point of view of activity. \\ Analysing relationships among work processes, health, and \\ subjectivation
}

\section{Resumo}

O Programa de Saúde da Família (PSF) surge como uma estratégia de reorganização da assistência à saúde pública do Brasil, com rápida expansão de cobertura populacional, ampliando o número de contratados. Seu foco de mudanças pretendido é o processo de trabalho, com a implementação de mudanças tecnológico-organizacionais que visam aumentar a resolutividade das ações de saúde no âmbito da Atenção Básica, colocando novos desafios para os profissionais de saúde. Procuramos analisar as relações entre os processos de trabalho, saúde e subjetivação em uma Unidade Básica de Saúde do sul do país que opera o Programa de Saúde da Família, orientados pelo ponto de vista da atividade. Detectamos lacunas entre as normas prescritivas do PSF e as situações concretas de trabalho, frente às quais os profissionais procuravam viabilizar a luta pela saúde, (re)normatizando seus meios de trabalho. A partir do tipo de gestão encaminhada na Unidade, o trabalho constituiu-se como uma zona de desenvolvimento potencial de invenção, permitindo o enlace entre a eficácia de suas ações e a criatividade, colaborando para fortalecer a luta pela sua saúde.

Palavras-chaves: Sistema Único de Saúde, Programa de Saúde da Família, atividade de trabalho, capacidade normativa.

\begin{abstract}
PSF (Programa de Saúde da Família - Family Health Program) is a strategy aimed at reorganizing public primary care in Brazil. The program is quickly expanding its population coverage and increasing the number of hired professionals. Its focus lies in changing its work process by implementing technological and organizational alterations aimed at increasing effectiveness of actions in the context of primary care, thus posing new challenges to health-care professionals. In this study we seek to understand the relation between work processes, health and subjectivation in the context of the Family Health Program in a Primary Care Unit of the Unified Health System, the Brazilian public health system, in the South of the country, from the perspective of activity. We detected some gaps between PSF prescriptive tasks and the actual work situation, which motivated professionals to struggle for their health by (re)defining their working methods. Since this managerial system was adopted by the health unit, work process turned into a potential area for the development of inventiveness, which allowed joining efficiency and creativity, and helped strengthen their health gains.
\end{abstract}

Keywords: Public Health System, Primary Care Unit, Family Health Program, work activity, workers' health, regulative activity. 


\section{Introdução}

Neste artigo, pretende-se compreender - operando do ponto de vista da atividade - as relações entre os processos de trabalho, saúde e subjetivação no âmbito do Programa de Saúde da Família (PSF), em uma Unidade Básica de Saúde (UBS) do sul do país (SILVA, 2006).

O conceito de trabalho exige outros conceitos para estruturar-se e ter força de conhecimento, caso contrário é incorporado ideologicamente ao senso comum. Para pensá-lo em sua efetiva pertinência, como produção de todas as dimensões do viver do humano, faz-se necessário o conceito de processo de produção, assinalando que o processo de trabalho se dá sob determinadas relações de produção ${ }^{3}$. Já o conceito de processo de trabalho nos indica que se ater ao objeto e aos meios de trabalho (materiais e imateriais) não é suficiente, pois é a atividade humana que dá vida aos outros elementos (também eles inventados pelo humano).

Por outro lado, a Ergonomia da Atividade (GUÉRIN et al., 2001) nos orienta que diferentes pontos de vista estão presentes nas situações de trabalho, devendo ser considerados desde a análise da demanda de intervenção. Os autores assinalam que se poderiam adotar três grandes tipos de pontos de vista, que correspondem a diferentes leituras do funcionamento da empresa, de um empreendimento. Tais pontos de vista são orientados pelos resultados (o mais estruturado), pelas condições da produção ou pela atividade (que não tem tradução estruturada na empresa). A atividade relativa ao conteúdo do trabalho (o uso concreto dos humanos no ato de trabalhar, o modo como eles o realizam) nunca esteve até aqui presente como questão social em debate. Na intervenção ergonômica, busca-se colaborar para a confrontação destes pontos de vista e não focar na atividade por si mesma. Privilegiá-la tem sim um papel estratégico - pois que interroga os outros pontos de vista - na transformação do trabalho. Ler o funcionamento do trabalho no PSF a partir da atividade, no vai-e-vem com o conjunto de seus determinantes, além de sua fecundidade, revelase estratégico, dada sua sistemática invisibilização.

O conceito de processo de trabalho em saúde, segundo Peduzzi e Schraiber (2006), foi apresentado pela primeira vez no Brasil por Mendes Gonçalves (1979), usando conceitos do marxismo. Discípulo e colaborador de Donnangelo (anos 1960), pioneira estudiosa sobre a profissão médica, o mercado de trabalho em saúde e a Medicina como prática técnica e social, também tinha como objeto de estudo o trabalho médico. Só a partir dos anos 1980 ampliou-se o escopo, especialmente para a Enfermagem. Posteriormente, Merhy (2002), partindo desse patrimônio, incorpora outros referenciais, como a Análise Institucional (Castoriadis, entre outros) e Esquizoanálise (Deleuze-Guattari), à sua maneira. Busca operar com os conceitos marxistas de trabalho vivo (instituinte) e trabalho morto para entender o que denomina "trabalho vivo em ato". É assim que não temos neste artigo a pretensão de fazer um estudo do processo de trabalho do PSF, apenas explorar algumas pistas a partir da leitura do ponto de vista da atividade em curso.

Considerando inicialmente o campo mais geral da organização dos Serviços de Saúde no Brasil, ele sofreu uma inflexão com a institucionalização legal do Sistema Único de Saúde (SUS) em 1988, estabelecendo como princípios básicos universalidade, descentralização, integralidade e participação da comunidade na configuração de um novo modelo gerencial. Estes princípios constituíram-se em desafios para os trabalhadores envolvidos com a assistência.

Ao longo dos anos, observam-se diversas experimentações numa tentativa de concretização destes princípios no cotidiano da atenção à saúde. Viana e Dal Poz (1998) relatam que, na década de 1990, o Brasil passava por uma série de problemas decorrentes de mudanças econômicas, demográficas e epidemiológicas, determinando um quadro que eles chamaram de "crise da saúde". Reconhecia-se que o modelo de assistência até então hegemônico - hospitalocêntrico, individualista, com utilização "irracional" dos recursos tecnológicos disponíveis e baixa resolubilidade - oferecia obstáculos para a concretização dos princípios do SUS, conduzindo à sua reforma incremental, ou seja, "um conjunto de modificações no desenho e operação da política” (p. 16). Assim, a partir de 1994, o Ministério da Saúde (MS) adota o Programa de Saúde da Família (PSF) como ponto-chave do fortalecimento do SUS.

Esse programa é então apresentado como estratégia para reverter o modelo de assistência, prevendo novas práticas de saúde, integrando de forma permanente, nas Unidades Básicas de Saúde (UBS), ações clínicas e ações coletivas de saúde (prevenção e promoção da saúde). Ele estrutura-se por intermédio da Unidade de Saúde da Família (USF), na qual atua com uma equipe multiprofissional responsável por uma determinada população a ela vinculada, orientado por seis diretrizes básicas (BRASIL, 2004): substituição das práticas tradicionais por um novo processo de trabalho; compromisso com a integralidade e a intersetorialidade; territorialização; atuação em equipes multiprofissionais; responsabilização e vínculo das equipes com a população adscrita; e estímulo à participação popular e ao controle social.

A partir desses princípios, a estratégia Saúde da Família deixa de ser encarada em paralelo na organização dos serviços, como tradicionalmente os progra-

${ }^{3}$ No capitalismo, o processo de trabalho está subsumido ao processo de valorização de capital. 
mas foram desenvolvidos pelo Ministério da Saúde. Tornou-se uma proposta substitutiva e de reestruturação do modelo de atenção. Avançava em direção à idéia de Programação em Saúde, que

sempre foi uma prática marginal e limitada no tempo e no espaço, restringindo-se aos campos em que o Estado via-se obrigado a agir rápida e eficazmente por razões de ordem política, econômica ou mesmo sanitária (CAMPOS, 1991, p. 58).

Atestam a grande importância concedida a esta forma de estruturação dos serviços: o volume de investimentos, a implantação de Equipes de Saúde da Família (ESF) - sua presença passando de $55 \mathrm{mu}-$ nicípios em 1994 para 5.131 em 2007 -, assim como a expansão da cobertura populacional, que saltou de um milhão de pessoas em 1994 para 87 milhões em 2007 (BRASIL, 2007).

Essa expansão do PSF vem sendo monitorada e avaliada. Em 2004, vieram a público resultados de uma Avaliação Normativa do Programa Saúde da Família (BRASIL, 2004), realizada no período de 2001 a 2002, com 13.501 equipes de saúde da família de 3.778 municípios, consistindo na segunda avaliação de maior envergadura no país. Apresentando um caráter exclusivamente quantitativo e descritivo, resultou na caracterização da implantação e do funcionamento do programa no Brasil, indicando a dimensão dos "recursos humanos" como um de seus pontos mais fragilizados. Esta última é uma informação que nos chama atenção.

Essa avaliação foi realizada a partir dos critérios previamente definidos no desenho da proposta da Estratégia Saúde da Família (suas normas antecedentes) e, em nosso entendimento, apresenta a problemática dos "recursos humanos" sem discutir questões concretas acerca da transformação do modelo de atenção, como também oculta as singularidades e especificidades que cada Unidade de Saúde possa apresentar.

Em nossa revisão bibliográfica (até o ano 2006), identificamos que o processo de trabalho no PSF também vinha sendo foco de investigações acadêmicas. Entre estes estudos (a seguir), destacamos dois aspectos que instigaram nosso questionamento quanto ao que estaria em jogo com a transformação do modelo de atenção: primeiramente, a maioria destes estudos ora limita-se à descrição das atividades realizadas, ora focaliza-se na percepção dos usuários, dos gerentes do programa e dos próprios profissionais, permanecendo como ponto cego de análise a perspectiva da atividade de trabalho; outro aspecto remete aos "recursos humanos" como problema não resolvido, o que coincidia com os resultados da avaliação normativa do Ministério da Saúde.

Souza e Sampaio (2002) relatam estudos que apontam como dificuldades para a consolidação e o sucesso do programa a rotatividade dos profissionais, a insatisfação com as formas de contratação, a qualificação dos recursos humanos e a dimensão técni- ca e política da gerência e da gestão. Conill (2002) investigou a implantação do PSF em FlorianópolisSC a partir de duas categorias operativas: o acesso e a integralidade. Utilizou-se de uma metodologia avaliativa usando triangulação de métodos, fontes e dados: num primeiro momento, contextualizaram-se as políticas municipais, analisando a temática a partir de entrevistas semi-estruturadas com técnicos e gestores, documentos, atos legislativos e observação participante da IV Conferência Municipal de Saúde e, num segundo momento, estudaram-se, numa amostra intencional, as práticas de cinco equipes por meio de observação direta, entrevistas, documentos e análise quantitativa do Sistema de Informação da Atenção Básica. Por fim, incluiu-se no estudo a opinião de vinte famílias, quatro por equipe. Ao discutir as problemáticas da implantação do PSF em Florianópolis, a questão dos "recursos humanos" é assinalada como central: "recrutamento, capacitação, motivação, supervisão e rotatividade foram os principais problemas apontados" (p. 196).

Caetano e Dain (2002) discutem as dificuldades de expansão, destacando a questão dos grandes centros urbanos e reiterando a questão dos "recursos humanos” disponíveis. Ribeiro, Pires e Blank (2004) realizaram uma revisão bibliográfica acerca do trabalho no âmbito do PSF e constataram o reconhecimento do PSF em seu potencial positivo de mudança, ao lado de limitações, como as precárias condições de trabalho, associadas à "composição básica insuficiente das equipes, insuficiência de profissionais com o perfil proposto pelo Programa [...]” (p. 442).

Esse quadro nos conduziu a colocar em análise por que se entende que os "recursos humanos" disponíveis e sua qualificação têm constituído um problema para o desenvolvimento bem-sucedido do PSF? Quais desafios, dificuldades e obstáculos vêm sendo colocados aos trabalhadores em sua atividade de trabalho? O que é necessário para se atingir os objetivos propostos pelo PSF? Quais estratégias vêm sendo operadas para o enfrentamento das variabilidades e dificuldades da atividade de trabalho em saúde frente à pressão por resultados?

Em outra direção, Dal Pai e Lautert (2004), no estudo da percepção de onze agentes comunitários de saúde (ACS) do Programa de Agentes Comunitários (PACS) de uma cidade do Rio Grande do Sul, chegaram ao que seriam as duas questões centrais para os agentes: a busca de confiança e reconhecimento no trabalho, dimensões fundamentais para o registro da identidade cuja argumentação acerca da psicodinâmica do reconhecimento no trabalho pode ser encontrada em Dejours (2004). As autoras detectaram o desconhecimento do espaço de atuação deste tipo de profissional, assinalando para a insuficiência de seu treinamento e a ausência de delimitações claras quanto ao seu papel no interior do Programa de Agentes Comunitários (PACS). Fatores estes que poderiam estar bloqueando o melhor encaminhamento de uma 
dinâmica de reconhecimento do trabalho, limitando a potencialidade de seu trabalho.

A partir do que nos sinalizava a pesquisa bibliográfica, realizamos, em uma Unidade Básica de Saúde do município de Londrina (PR), uma investigação sobre as transformações do trabalho em saúde no PSF sob o ponto de vista da atividade, destacando os desafios colocados para seus profissionais e suas tentativas de superação e considerando as relações com os processos de saúde e subjetivação. Neste artigo, procuramos colocar em discussão algumas das questões emergentes desta investigação após apresentarmos nossos referenciais, que têm embasamento nas perspectivas vitalista de saúde (CANGUILHEM, 2000, 2001) e ergológica da atividade (SCHWARTZ, 2004; SCHWARTZ e DERRIVE, 2007), em sua orientação mais geral, buscando operar com ferramentas conceituais geradas pelas abordagens clínicas do trabalho, especialmente a Ergonomia da Atividade, a Psicodinâmica do Trabalho e a Clínica da Atividade.

\section{Saúde, do que se trata?}

A tendência da vida está em se afirmar na mudança e na invenção, na atividade, para além da inércia e da indiferença. Logo, a vida não está fundamentalmente no campo da previsibilidade, mas no evento, no inédito, na indeterminação e na complexidade.

A saúde é, conforme Canguilhem (2005), antes de tudo, um valor. Segundo Caponi (1997), ele introduz uma importante inversão nos estudos sobre a saúde, que deixa de ser definida por oposição à doença e se constitui enquanto "normatividade", capacidade de criar novas normas, valores e modos de viver frente às "infidelidades do meio", variações e imprevistos inerentes à própria vida. A doença expressaria a perda da capacidade de ser normativo, sendo uma norma de vida inferior.

Essa concepção de Canguilhem (2005) introduz algo que escapa às medições, o que ele chamou de corpo subjetivo, aludindo à experiência singular, habilitando qualquer pessoa a falar sobre a própria saúde. Isto não significa uma rejeição do conhecimento científico, mas enfatiza a articulação do saber médico com aquilo que cada um de nós, e somente cada um de nós, pode dizer a respeito de nossa situação e dos sintomas pelos quais somos acometidos.

Tratando-se da assistência à saúde, esses pressupostos podem ser explorados por diferentes vias. Uma primeira refere-se à organização das práticas de saúde, que devem estar comprometidas não com o controle dos indivíduos, mas com a ampliação de sua "margem de segurança”, com a restituição e o fortalecimento de sua capacidade normativa frente às variações da vida. Outra via está em adotar o conceito de corpo subjetivo, colocando no centro das práticas de saúde a compreensão de que cada indivíduo está habilitado a falar da própria saúde. Percebemos então que os profissionais de saúde, no momento do cuidado, deparam-se com as normas produzidas pelos próprios usuários dos serviços, recentrando o meio em torno de seu próprio meio (CANGUILHEM, 2001). Este debate traz à tona a complexidade e a singularidade presentes no trabalho em saúde enquanto co-produção de um serviço (ZARIFIAN, 2001), remetendo inclusive à discussão acerca de que serviço se trata.

Problematizar o trabalho em saúde por esta via coloca outros elementos na discussão, por exemplo, quanto aos recursos necessários para uma atenção mais efetiva à saúde, destacando que a busca de competência profissional e eficácia das ações tem de incorporar uma perspectiva muito mais compreensiva do que prescritiva.

Nesse sentido, para a efetuação do trabalho em saúde, seria fundamental a possibilidade de exercício da normatividade vital também para os próprios profissionais de saúde, no momento da assistência, implicada no encontro com a situação de cada usuário, sempre imprevisível.

\section{A relação entre trabalho, saúde e sub- jetivação}

Se nosso ponto de partida não é um vivente natural passivo, quando muito alguém que reage ao meio, a saúde passa a ser entendida como conquista, meta a ser atingida (DEJOURS, 1986). Falar de saúde nos obriga então a falar do trabalho:

[...] pois ele é central na definição de nosso meio, não só porque a ele dedicamos muito de nosso tempo (mesmo quando desempregados), como também porque grande parte de nossas condições de vida está relacionada com o trabalho que temos (BRITO et al., 2003, p. 30)

O trabalho envolve tanto as relações entre os humanos, quanto entre eles e o meio onde se trabalha e vive. Podemos mesmo afirmar que o trabalho é uma atividade que tem uma finalidade, mas também é o momento em "que se pode pôr em prática a capacidade humana de se reapropriar das situações e reinventá-las, instituindo novas regras e normas" (BRITO et al., 2003, p. 39).

O entendimento do trabalho como (re)produção de si e do mundo nos impede de pensar que os trabalhadores se adaptam passivamente aos imperativos aí presentes. Ora, trabalhar nunca é um fazer neutro em relação à saúde, pois "através das diferentes relações estabelecidas entre o indivíduo e seu trabalho, a saúde é implicada no mais alto nível” (DEJOURS, 1993, p. 99). A questão bem colocada não seria trabalhar ou não trabalhar, mas sim: qual trabalho? Já a Ergonomia havia colocado em seus começos sua descoberta: adaptar o trabalho ao homem e não o contrário, como predominante. 
Preferimos tratar a dimensão psicológica presente no trabalho descentrando a questão do sujeito para a da subjetivação. Buscamos passar ao largo da dicotomia sujeito-objeto, historicamente construída, pois o que temos é uma história de diferentes modos de subjetivação na cultura. Ou seja, nossa referência não é um sujeito substancializado, cuja vida psicológica estaria no seu interior, individualizado. Estamos interessados na criação de modos de existência, na invenção de novas possibilidades de vida.

\section{Interrogações sobre o trabalhar: as contribuições do ponto de vista da atividade}

Nesta perspectiva, recorremos ao conceito de atividade de trabalho, conceito transversal, imprescindível para a sinergia entre diferentes disciplinas e abordagens científicas na relação com os saberes da prática. A Ergonomia francofônica apreende o trabalhar destacando o prescrito do realizado, apontando o hiato entre estas duas dimensões. Descobriu-se que trabalhar nunca se reduz à simples e fiel aplicação de métodos e procedimentos, como se acreditava com o taylorismo ${ }^{4}$. Frente ao que foi antecipado, para que os objetivos e resultados previamente determinados sejam atingidos, os humanos são desafiados a mobilizarse inteiramente.

Nas situações concretas de trabalho, temos a presença de uma diversidade de normas, muitas vezes contraditórias. Compreender a forma como os processos de saúde, subjetivação e trabalho estão intricados exige uma capacidade de apreender tais normas impostas-propostas, seus limites, inclusive as normas dos usuários. O trabalho se apresenta então como lugar de debate de normas e valores, de microescolhas, orientadas pela busca de "modos de fazer face" ao hiato apontado. Assim, os trabalhadores renormatizam o meio de trabalho - recentrando o meio como seu meio (Canguilhem, 2001) - com freqüência ampliando a singularidade da situação, o que gera efeitos no plano da produção de novas variabilidades e da complexidade do sistema.

Operar com o conceito de atividade ajuda no acesso ao "algo mais" investido por aqueles que trabalham para dar conta das exigências, a dos outros e as suas. Se trabalhar nunca é pura execução do que foi antecipado, sempre envolverá uma confrontação com aquilo que preexiste à atividade e persiste. Nesse sentido, conforme Schwartz (1992), trabalhar envolve sempre "dramáticas de uso de si" ${ }^{5}$ - do uso de suas próprias capacidades, recursos e escolhas - por outrem e por si, dando nobreza à contribuição do trabalhador (individual e coletivo), sempre negada, negligenciada ou considerada de menor valor ou "natural" (conforme o caso do trabalho doméstico feminino). Existe sempre uma tensão na articulação dessas duas modalidades de uso de si. Somente na negociação entre os usos de si, por si e pelos outros - sempre por (re)fazer, nem sempre bem-sucedida - é que o trabalho pode ser operador de saúde, permitindo o exercício de sua capacidade normativa. Mas pode tornar-se operador de adoecimento (sofrimento patogênico), quando não se consegue realizar satisfatoriamente o debate de normas e valores.

Partindo da clássica descoberta da Ergonomia, diferenciando "trabalho prescrito" e "trabalho real", assim como sinalizando as regulações mobilizadas pelos operadores, empreendidas para dar conta dos equívocos da prescrição e da presença de variabilidades, encontramos um movimento conjunto de ampliação do conceito de atividade, retirando-o da camisa de força comportamentalista. O caráter sempre enigmático do trabalho, excedendo as antecipações e formas de conhecimento já existentes, é apreendido por Dejours $(1997,2004)$ enquanto real do trabalho, ao passo que Clot $(2006,2008)$ prefere assinalar o que está em jogo como real da atividade.

No caso da Psicodinâmica, Dejours (1997) já chamara atenção que o trabalho se constitui na relação com o que denomina $o$ real do trabalho. Com este substantivo, refere-se a algo cuja realidade "se caracteriza por sua resistência à descrição. (Ele) é a parte da realidade que resiste à simbolização" (p. 41), remetendo aos limites do saber, do conhecimento e da concepção prévia. Tudo isso encaminha para a seguinte definição do trabalho:

[...] é a atividade coordenada desenvolvida por homens e mulheres para enfrentar aquilo que, em uma tarefa utilitária, não pode ser obtido pela execução estrita da organização prescrita. (idem, p. 43)

Enfim, agregando a riqueza oriunda do conceito de "atividade subjetivante", ele traz para a teoria os conceitos de (resistência do) real, de revés e da compensação deste baque por processos imprescritíveis, que implicam a subjetividade. Uma complexa produção psíquica e cultural que procede da "experiência da prática”, uma "inteligência astuciosa”, "corporal” e que exige passar por julgamento do outro (caracterizando-se a dinâmica para transformar-se em sabedoria da prática, cf. DEJOURS, 2004). Verifica-se então o

\footnotetext{
${ }^{4}$ Paradoxalmente, esta mesma crença pode ser encontrada em muitos de seus críticos (Oddone et al., 1981; Schwartz, 1992).

${ }^{5}$ Para Schwartz (1992), “(...) o trabalho humano é lugar onde se opera uma dialética, portanto, um uso problemático de si mesmo e pode se definir talvez do seguinte modo: num primeiro registro, ele diz respeito aos antecedentes normatizando e antecipando a atividade (...) num segundo registro, ele comporta a insubstituível gestão das dimensões singulares da situação que marca na atividade cotidiana de trabalho os elementos variáveis, históricos de toda situação, sua não repetição integral” (p. 53).
} 
que em Psicodinâmica se denomina dinâmica do reconhecimento ${ }^{6}$, decisiva para o fortalecimento da identidade, ossatura da saúde, em termos psicossomáticos.

No caso da Clínica da Atividade, Clot (2006) busca enriquecer o conceito de atividade com outros referenciais, evitando o risco de uma concepção amorfa ao incorporar os conflitos que a constituem. Desdobra o conceito em atividade realizada e real da atividade. Como já sabemos, a atividade realizada é entendida como "aquilo que se faz", o que se apresenta no plano comportamental, dos modos operatórios diretamente observáveis, uma parte ínfima do que se pode fazer, sendo, portanto, uma atualização de uma das atividades possíveis na execução da tarefa. O real da atividade envolve também aquilo que não se faz, o que se procura fazer sem lograr êxito. Explorando Vigotski, ele assinala que as atividades contrariadas, suspensas ou impedidas devem também ser admitidas na análise, pois não estão ausentes da vida do trabalho, ao contrário, emergem aí com destaque.

Nessa linhagem clínica, reafirmando o caráter ativo dos seres humanos, enfatiza-se a distinção entre organização prescrita do trabalho e aquela operada pelo trabalhador, remetendo a um esforço de re-organização das tarefas pelos coletivos profissionais, o que sinaliza a re-criação da organização do trabalho pelo trabalho de (re)organização do coletivo ${ }^{7}$. Clot (2006a) procura dar ênfase diversa da que encontra na Psicodinâmica. Coloca em questão a sobredeterminação da subjetividade pelo sofrimento - que seria fundador, originário (CLOT, 1995) - pois, para ele, este real é mais uma prova que constrangimentos. Clot (2006) considera muito direta, na Psicodinâmica, a passagem do real de situação de prova a sofrimento psíquico. Para ele, "trabalhar é também, sem cessar, 'instrumentar' um meio para viver (...)” (idem, p. 253). Se para Dejours (2004) o trabalho é, por definição, humano, pois que o convoca precisamente onde a ordem tecnológica-maquinal é insuficiente, Clot (2006) busca reverter a questão: a ordem tecnológica é humana, em seu princípio, porque se é convocado justamente lá onde o trabalho, por exceder seus limites, busca economizar-se com a ajuda de artefatos” (idem, p. 256).

Esta abordagem desenvolvimental agrega outros conceitos de Vigotski (2000), como o de "zonas de desenvolvimento potencial”, operada pelos coletivos de trabalho. Agrega também conceitos de Bakhtin (2000) para pensar o real da atividade, frente ao qual se mobiliza o que se vai denominar gênero profissional. Ou seja, entre o prescrito e a atividade, existe um terceiro termo, o prescrito informal - partilhado em um dado meio profissional, uma espécie de prescrição coleti- va - chamado de "gênero profissional" (CLOT, 2006). Este assume uma função psicológica importante, pois, além de colaborar do ponto de vista organizacional, vai também representar um recurso para a própria ação. Quando o coletivo de trabalho não consegue construir um gênero profissional, o trabalho de algum modo se enfraquece. Cada trabalhador é reenviado para si próprio e a função psicológica que o trabalho organizativo assume não pode ser viabilizada, gerando sofrimento patogênico, colocando em xeque a confiabilidade do material e a eficácia do trabalho, podendo mesmo gerar acidentes.

Schwartz (1988, 2004), desde os anos 1980 desenvolvendo as possibilidades contidas no Modelo Operário Italiano, apresenta-nos uma formulação mais precisa a partir dos anos 1990 com "dispositivo dinâmico de três pólos”. A partir da crítica ao dispositivo Comunidade Científica Ampliada, formulado por Oddone, Re e Brianti (1981), ele entende que aquele regime de produção de saberes não só contava com os saberes científicos e os da prática, mas, através do sindicato, fazia uma heurística sinergia. Ou seja, Schwartz (2000) não só destaca a grande riqueza contida naquela experimentação italiana e suas proposições, como as critica (a fraca concepção do que é ciência, por exemplo, que se pretenderia "ampliar") e a faz avançar (assinala a ação de um terceiro ator, considerando que este papel poderia ser assumido por outros que não os sindicatos). Propõe um paradigma na forma de três pólos em relação sinérgica, sendo um deles o dos conceitos, que comporta o conhecimento sistematizado e estabilizado. O outro, o pólo dos saberes gerados/investidos nas atividades. Dado que se trata de um campo de cultura e incultura recíprocos, exigem um retrabalho sistemático e permanente de mútua validação e desenvolvimento.

Schwartz (2004) chama atenção para o caráter decisivo de um terceiro pólo, que trata das exigências éticas e epistemológicas, permitindo que o pólo científico seja afetado pela convocação das forças do outro pólo e desenvolva a necessária humildade epistêmica para retornar às atividades e ter possibilidade de aprendizagem.

Nesta perspectiva, entendemos que incorporar o possível e o impossível presentes no curso do trabalhar, incorporando os protagonistas da atividade (implicados em uma co-análise), permite nos aproximar do caráter singular da atividade de trabalho, acessando toda uma riqueza que faz do trabalho uma paixão.

A partir dos referenciais indicados, entendemos que investigar o trabalho do ponto de vista da atividade nos coloca desafios e também a exigência

\footnotetext{
${ }^{6} \mathrm{O}$ que exige a existência de um espaço público interno de discussão, quando se dá visibilidade às astúcias operadas, desde que havendo confiança (respeito às regras da profissão).

${ }^{7}$ Explorando Bakhtin, a Clínica da Atividade a isto denomina gênero profissional, que corresponde a um repertório de maneiras de agir, "obrigações", avaliações construídas pelos trabalhadores para a regulação de sua atividade.
} 
de composição de diferentes instrumentos teóricometodológicos.

Contudo, consideramos que incorporar o ponto de vista da atividade de trabalho implica relacionar comportamentos observáveis dos trabalhadores e elementos não observáveis - as decisões tomadas, o pensamento no trabalho, percepções e interpretações realizadas sobre sua própria atividade, ações não realizadas, modos operativos inventados e saberes-fazer construídos, acessados necessariamente com a confrontação de diferentes olhares: o do pesquisador e daquele que realiza a atividade. Por expressar a relação do trabalhador com conteúdos dados, a atividade é um objeto em construção e sua investigação deve ser realizada no terreno onde se desenrola: a situação de trabalho.

\section{Uma leitura das relações entre os pro- cessos de trabalho, saúde e subjetiva- ção no Programa de Saúde da Família sob o ponto de vista da atividade}

A investigação foi realizada em uma Unidade Básica de Saúde do município de Londrina, ao norte do Paraná, onde o PSF fora implementado há cinco anos. Ressalta-se que, no momento deste estudo, coexistiam naquela unidade profissionais que ainda não pertenciam ao PSF, mas, como estavam inseridos nas ESF, foram incluídos em nossa análise.

Acompanhamos o cotidiano do PSF ali em curso, visitando-o regularmente. Desenvolvemos conversas sobre o trabalho (ou entrevistas dialógicas), observações e registros das diversas atividades no curso da ação. Ficamos atentos à rede dialógica que aí circulava (diálogo no trabalho), recorrendo sempre que pertinente e possível a um novo diálogo com eles sobre seu trabalho, assim como sobre o diálogo desenvolvido no curso da ação.

Já havíamos realizado um estudo sobre os princípios do PSF nos manuais elaborados em nível ministerial, buscando compreender como eles eram operacionalizados no dia-a-dia daquela unidade. Logo no início de nosso estudo de campo, observamos uma série de situações que pareciam não estar previstas nos manuais, incompreensíveis numa aproximação apressada, colocando-se sempre a necessidade de um diálogo sobre o que ocorria com os protagonistas da atividade.

O cotidiano da unidade apresentou-se para nós como uma realidade dinâmica, dotada de uma complexidade marcada pela imprevisibilidade e instabilidade, na qual o trabalho não poderia se inscrever num caráter exclusivamente objetivo e previsível. Embora o PSF privilegie as atividades de assistência junto à comunidade em ações de promoção e prevenção à saúde, observamos que os usuários, quando sentiam necessidade, ainda recorriam à unidade à procura de consultas médicas, seguindo a lógica existente antes da implementação do PSF.

Surpreendemo-nos com a importância estratégica do setor de recepção na unidade, lócus onde se iniciam os primeiros encontros com as normas de vida dos usuários, constituindo os desafios iniciais dos profissionais de saúde. Destacamos duas atribuições da recepção, o agendamento de consultas (seja na unidade, seja em outros serviços de saúde especializados) e a marcação de exames.

Percebemos que o agendamento de consulta não consistia em um processo mecânico de relacionar os pedidos com a disponibilidade de vagas e horários. Para articular este momento do processo de trabalho com a proposta do PSF, sua configuração era resultado da regulação operada pelo recepcionista. Nesse sentido, constitui-se uma "relação de serviço" (ZARIFIAN, 2001): quando o usuário solicita uma consulta médica, inicia-se um processo em que o recepcionista busca saber-compreender a queixa do usuário, acessar seu histórico no computador e verificar: (a) sua situação vacinal, (b) se ele se consulta com outros especialistas, (c) se faz uso de alguma medicação, (d) seu endereço no cartão SUS, (e) qual ESF é responsável pela área onde o usuário reside. Contando com estas informações, o recepcionista pode (ou não) solicitar uma pré-consulta com um auxiliar de enfermagem da ESF no momento do pedido de consulta, o qual escutará o usuário e avaliará a necessidade de uma consulta médica ou algum outro encaminhamento, alimentando um círculo virtuoso de cuidado com a saúde.

A realização de todos esses procedimentos no momento de agendar uma consulta é orientada segundo valores e normas de atendimento construídos e acordados entre os profissionais, seja durante realização de suas atividades, nos encontros pelo corredor da unidade, nas reuniões de equipe, como também na hora do cafezinho, do almoço etc. Na perspectiva de realizar o atendimento segundo os princípios do PSF (conforme entendimento pessoal e do coletivo de trabalho da unidade investigada), uma das normas acordadas entre aqueles profissionais é não deixar nenhum usuário ir embora da unidade sem ser escutado. Sim, pois ele pode estar com a vacinação atrasada, algo ainda não detectado pela ESF responsável, ou pode estar com pressão alta, ou precisando de alguma medicação disponível na unidade!

O momento de agendamento de consulta apresentava-se ali como uma ponte entre um modelo centrado no atendimento à doença (com a restrição da ação à consulta médica) e o PSF (modelo que visa primeiro à prevenção e à orientação de cuidados à saúde).

Apreendemos que a decisão deste modo de "recepcionar" os usuários foi resultado de um debate envolvendo elementos técnico-estratégicos e valores, o que na maioria dos casos ocorria durante a atividade de trabalho, como também um acordo entre os diversos 
profissionais - auxiliar administrativo (recepcionista), auxiliar de enfermagem, agente comunitário, enfermeiros e a coordenadora da unidade - em que cada um acrescentou dados vitais para tornar o processo articulado com o PSF e assim transformar realmente o modelo de atenção. A coordenadora reconhece a necessidade de negociar para organizar o trabalho nos moldes do PSF, como coloca em um de nossos diálogos:

Aqui na unidade eu negocio o tempo todo [...] Aqui só funciona na negociação, negociamos o tempo todo. (X., coordenadora da UBS, referindo-se a ela e aos outros profissionais de saúde)

Indagada sobre o que significa este "negociar", a coordenadora relata um exemplo sobre um ponto importante do trabalho em equipe: a divisão de informações acerca dos usuários:

Aqui cada um é diferente. Por exemplo, a Y. [auxiliar de enfermagem] está na unidade há muitos anos, acha que sabe fazer e que não precisa ficar explicando, mostrando suas informações pra ninguém. Só que a gente precisa sistematizar as informações, dividí-las. Ela mesmo diz: 'eu guardo de cabeça todos os meus pacientes hipertensos, não preciso fazer listas'. Com ela eu preciso ter tato, valorizo sua experiência e aí eu brinco: se você ganhar na mega sena e sumir, como vou ter os dados que preciso para continuar o trabalho? (X., coordenadora da UBS)

Já com a W. [auxiliar de enfermagem] é mais tranqüilo. Quando ela diz que também sabe de cor seus pacientes e que não precisa fazer lista, eu brinco: como vou fazer para supervisionar seu trabalho, vou rachar sua cabeça para olhar dentro? Todo mundo ri e ela acaba entendendo o que eu quero. (idem)

Garantir essa (re)organização do trabalho, fruto da capacidade normativa por parte dos profissionais de saúde, exige que o auxiliar administrativo, em sua atividade de recepcionar, coloque em debate os valores acordados na unidade e os valores do próprio usuário (que, na maioria das vezes, ainda acredita resolver seu problema apenas com uma consulta médica). Ao estar presente numa situação de agendamento de consulta, o recepcionista explica como lida com esta nova norma na entrada da unidade e também como essas normas são construídas, apresentadas respectivamente:

Se eu explicasse para ele que eu não posso dispensar ninguém no balcão sem saber o que tá acontecendo, o motivo pelo qual ele busca essa consulta, não faz sentido porque ele ia dizer que ele tem diagnóstico [...]. Então eu tentei jogar essas perguntas aí pra tentar convencê-lo a ficar. Mas você viu que não foi muito suficiente, porque [...] ele não quer pra agora, ele achou que essas intervenções não seriam pertinentes. Não seria necessário. [...] que iria ajudar mesmo é o que ele tava preocupado nesse momento com as crianças dele que estavam em casa sozinhas. Eu tinha que entender isso daí. Porque as crianças pequenas, sozinhas em casa, ele tava preocupado. Então eu vim aqui dentro pedi para apressar e aí entrou. (auxiliar administrativo, recepcionista da UBS)
[...] você percebe que a gente sempre conversa um com outro, fazendo uma espécie de uma discussão de caso. Aí eu relembro, como eu te falei, as informações são muitas e alguém pode esquecer. E eu organizo assim, eu não esqueço, então eu fico lembrando. (idem)

Salientamos toda a importância do auxiliar administrativo/recepcionista, não obstante este trabalhador não pertencer oficialmente à composição prevista da equipe. Observamos a importância da articulação de seu trabalho com o dos demais, de modo que a gestão realizada na "entrada"/recepção da unidade contribuía para a ordenação das atividades do PSF. Por exemplo, garantindo a cobertura vacinal, na medida em que cada usuário que chega à unidade tem seu histórico verificado, potencializando os objetivos do PSF.

Encontramos, nesta unidade, profissionais capazes de renovar seus meios de trabalho segundo seus valores, instituindo novas normas no confronto com a realidade imposta, superando as diferentes limitações de concretização do programa. Ou seja, no seio da atividade de trabalho, constatamos que o conjunto de desafios a serem enfrentados naquele contexto constituiu uma "zona de desenvolvimento potencial" (CLOT, 2006), oportunidade de encaminhamento de uma certa maneira de trabalhar que tem garantido à unidade o reconhecimento quanto à sua eficácia, tanto por parte da Secretaria Municipal de Saúde quanto por diferentes pesquisadores que circularam pela unidade, interessados em estudar uma experimentação considerada bem-sucedida.

As normas do PSF não aludem à recepção, seja de uma Unidade Básica, seja de uma Unidade de Saúde da Família. Verificamos nestas normas as indicações do como "deve ser" este novo modelo de assistência à saúde, com a inclusão de alguns instrumentos que englobam as informações que devem ser priorizadas, mas apresentando uma lacuna do "como fazer", como operacionalizá-lo. Ao explorar a ótica da atividade, identificamos que, frente a este vazio de normas (SCHWARTZ, 2000), esta ausência do "como fazer" não gerou trabalhadores perdidos, passivos, impotentes no "como proceder".

Na unidade estudada, a capacidade normativa não se revelou limitada, bloqueada, impedida, ao contrário, percebemos que se produzia um espaço potencial de gestão. Quanto à luta pela saúde no trabalho, lembramos a importância da possibilidade de se reapropriar do meio e reinventá-lo segundo seus anseios, de forma que é a variabilidade e não a repetição que são favoráveis à saúde. Esta questão foi explicitada pela fala da coordenadora da unidade:

Por outro lado, você vê a insatisfação dos funcionários, que eles estão exaustos. Agora se vê uma coisa que me chamou atenção aqui é o número de atestados que diminuiu, de atestados médicos. [...] Absenteísmo! Assim, porque eu acho que eu lidava com muito mais atestados. Tô me dando conta agora falando pra você, porque eles ficam 
exauridos, com aquela, não tem uma motivação pro futuro. [...] Acho que essa brecha da reorganização dá uma questão de otimismo de acreditar de que isso não vai ser sempre assim [...] (X., coordenadora da UBS)

\section{As diretrizes do PSF e o ponto de vista da atividade: os possíveis e os impossí- veis nesta modalidade de assistência à saúde}

Consideremos quatro das diretrizes do PSF à luz da atividade em algumas ações observadas no cotidiano da unidade. Destacamos a dimensão oculta do fazer em saúde no serviço investigado, bem como o esforço de gestão dos seus profissionais. Lembramos que, dentro das diretrizes do PSF, tanto a equipe de saúde como seus componentes apresentam atribuições específicas, não tratadas neste artigo.

\section{a) A substituição das práticas tradicionais por um novo processo de trabalho e a territorialização}

Essas diretrizes prevêem uma assistência à saúde voltada para as necessidades de saúde da população, para a solução de problemas, prevenção de agravos à saúde e promoção da qualidade de vida, em vez de oferta exclusiva de consultas médicas.

Para a substituição das práticas tradicionais, uma das principais responsabilidades da equipe de saúde da família é o conhecimento da realidade local sob sua responsabilidade - seus aspectos socioeconômicos, culturais, geográficos e epidemiológicos. Baseado nisso, realizar-se-á o planejamento, a programação de atividades e a reestruturação do processo de trabalho, atividades realizadas com a participação da "comunidade”, estando intimamente relacionada com sua outra diretriz, a territorialização. Ela corresponde à definição da área de abrangência de atuação da equipe e ao cadastramento da população a ela referida. A partir disso se dá o acompanhamento das situações de exposição a agravos, das condições de vida, das ações programáticas desenvolvidas e da situação de saúde das famílias e da comunidade a ela vinculadas, melhorando a capacidade de identificação de desigualdades entre os diferentes grupos para melhor planejar as ações de saúde. Para o Ministério da Saúde (BRASIL, 2003), esta diretriz aponta a potencialidade que o programa tem em resgatar os vínculos de compromisso e de co-responsabilidade entre os serviços de saúde, os profissionais e a população (outra diretriz discutida mais adiante).

Seguindo estas diretrizes, encontramos como uma das atribuições do agente comunitário de saúde (ACS) o mapeamento de sua área de abrangência, o cadastro das famílias e sua atualização permanentemente. O cadastro das famílias foi citado como muito eficien- te, até mesmo imprescindível, por vários profissionais das equipes, o que então investigamos.

O instrumento para realização desse cadastro é a chamada ficha $A$, padronizada para o PSF em todo o Brasil, que agrupa informações de pessoas com 15 anos ou mais das famílias adscritas à área de abrangência, como endereço, número da microárea e área, data de nascimento, idade, sexo, se é alfabetizado, ocupação e doença ou condição referida. Porém, observamos que tal ficha não era utilizada na rotina de trabalho do agente comunitário! Em seu lugar, era utilizado o que se chamava caderno, elaborado pelos próprios agentes.

Ao indagarmos aos profissionais o porquê do não uso da ficha $A$, descobrimos que a ficha fora preenchida num primeiro cadastro e sua substituição estava relacionada com outra responsabilidade, a visita domiciliar (VD). A realização da visita é agendada por área de abrangência, momento em que os agentes carregavam consigo apenas as fichas dos residentes da área selecionada. No entanto, durante a visita na comunidade, usuários de outras áreas de abrangência muitas vezes solicitavam algum tipo de ajuda. Não tendo suas fichas em mãos, não podiam ajudar naquele momento, sendo necessário retornar à unidade. Dependendo da urgência, interrompia-se a continuidade e o planejamento do dia.

A partir deste limite (impossível?) de sua atividade, os agentes elaboraram uma série de cadernos, forma encontrada para ter, durante as visitas, informações de todos os usuários de sua responsabilidade, independentemente da área visitada em determinado dia. Os agentes transferiam as informações da ficha $A$ para seu caderno, de modo que, a cada visita domiciliar, se necessário, atualizavam este cadastro, incluindo aí a situação vacinal do usuário. Na maioria dos casos, eles não precisavam retornar à unidade para obter informações frente às ocorrências de seu cotidiano de trabalho, assistindo aos usuários, não precisando retirar da unidade as fichas $A$, que ficam arquivadas, não correndo o risco de perdê-las.

A atividade de trabalho dos agentes apresentouse dividida em dois momentos: um fora da unidade, realizando visitas domiciliares e reuniões com os usuários; outro dentro da unidade, atualizando seus diferentes registros, algo ausente na proposta oficial do PSF. Reorganizar as informações, dando a elas sentido, bifurcava-se em novas exigências em termos de instrumentos de trabalho (escassos) na unidade, como mesas e cadeiras. Sim, pois para que os doze agentes pudessem (re)organizar suas informações, operando sua competência compreensiva, paradoxalmente geravam o agravamento da precarização das condições de trabalho. Para afirmar a vida da profissão, observamos um improviso, na forma de um jeitinho: muitas vezes, os agentes comunitários sentavam em uma pia desativada para pensar e realizar suas anotações... O espaço físico instituído e seus móveis revelavam a 
ignorância da atividade, mesmo do trabalho efetivamente realizado, pois eles eram insuficientes para incorporar esta dimensão da atividade de trabalho dos agentes comunitários.

Atentemos para o relato de uma agente que expressa bem esse quadro. Em uma Pré-Conferência de Saúde do município, os Conselhos Locais de Saúde foram convocados para discutir prioridades para as unidades. A agente comunitária D., representando os profissionais de saúde junto ao seu Conselho, colocou como uma das prioridades da unidade a aquisição de materiais e equipamentos de escritório. Isso causou polêmica no grupo de discussão. A agente narra o debate:

Eu fui pra reunião sem saber o que ia falar, mas a X. [coordenadora da unidade] pediu pra eu ir. [...] Mas quando eu ouvi outros agentes e profissionais de saúde dizendo que o ACS não precisava de cadeiras ou mesas para trabalhar, que lugar de ACS era na rua eu retruquei: vocês não escrevem? Como é que vocês lidam com suas informações? Porque eu tenho meu caderno com minhas anotações e preciso estar sempre atualizando; vou fazer isso em pé? (D., ACS)

Os cadernos compõem uma rede de informações sobre os moradores da área de abrangência da UBS, contemplando:

- caderno de cadastramento das famílias adscritas ao PSF:

- caderno índice, que registra os usuários adscritos em ordem alfabética, cada qual apresentando uma numeração que é colocada em sua ficha de aprazamento e no cartão do usuário. O objetivo deste caderno é facilitar a localização das fichas de aprazamento dos usuários durante as ações de saúde (reuniões de hipertensos, diabéticos etc.). Isso permite o controle dos usuários assistidos e não assistidos (que são separados no momento da atenção), identificando rapidamente os faltosos, a partir da qual se organiza sua busca ativa. Este caderno contribui ainda para um maior conhecimento dos usuários das áreas de abrangência, pois, com a busca ativa organizada, a equipe descobre mais facilmente os motivos das faltas às reuniões. Por exemplo, usuários que trabalham e não podem comparecer, ou mesmo que não podem se locomover.

- caderno de faixa etária, elaborado para reconhecer o número de usuários com a mesma idade, localizando mais rapidamente os grupos a serem vacinados - idosos, adolescentes e crianças - e facilitando sua atualização (inclui usuários que mudam de faixa etária, como as crianças, ou exclui usuários que se mudam ou morrem).

b) A atuação em equipes multiprofissionais, responsabilização e o vínculo das equipes com a população adscrita

Dentre as normas do PSF, está a atuação em equipes multiprofissionais, cujo objetivo seria possibilitar o conhecimento mais amplo nas intervenções de saú- de, o que, segundo o Ministério, superaria a fragmentação gerada pelo excesso de especializações e conferiria maior eficiência aos serviços de saúde.

São descritas as atribuições gerais da equipe e também especificadas as atribuições de cada um dos seus componentes - médico, enfermeiro, auxiliar de enfermagem e agente comunitário de saúde. Contudo, não encontramos orientações acerca de como se processaria a articulação das diferentes atribuições de cada profissional da equipe a fim de atingir seus objetivos.

Identificamos uma forma peculiar na potencialização do trabalho em equipe: sua (re)organização, discriminando as equipes por cores. $\mathrm{Na}$ implementação do PSF, a coordenadora da unidade em foco relatou que as equipes existiam somente na prescrição, apontando dificuldades na construção do trabalho coletivo. O que de fato existia na unidade era a divisão por profissionais, ou seja, agentes comunitários trocavam informações somente entre eles e assim para os demais segmentos profissionais. Junto a esta questão, acrescentava-se outra dificuldade: a identificação dos prontuários dos usuários de responsabilidade de cada equipe, pois eram todos misturados.

Diante da identificação destes limites ao exercício da atividade de trabalho, as equipes foram discriminadas por cores. Assim, cada uma delas passou a ter uma cor: a equipe A é azul, a B é vermelha e a $C$ é verde. Com a separação, os prontuários da equipe verde são identificados com uma fita verde, por exemplo, agilizando a identificação de seus usuários.

A reorganização da equipe por cores, resultado da renormatização no seio da atividade de trabalho, permitiu não só a construção efetiva do trabalho em equipe, como também inseriu novas normas de trabalho na unidade como um todo.

Quanto às equipes, a divisão por cores criou outro tipo de referência, o elo de ligação entre os profissionais de cada uma, de modo que os poucos assuntos relacionados aos usuários eram discutidos prioritariamente com aqueles da equipe de mesma cor.

Concomitantemente, novos modos de comunicação foram criados na unidade, seja entre profissionais das diferentes equipes, seja entre eles e profissionais que não pertenciam ao PSF. Na recepção e nos lugares de circulação de usuários, existiam cartazes que discriminavam, nas cores da equipe, as ruas pelas quais ela era responsável, os dias e os horários de atividades na comunidade. Por exemplo, quando o usuário chegava à recepção com algum tipo de solicitação, aquele que o atendia verificava no seu cartão SUS o endereço e identificava nos cartazes a equipe responsável por este usuário para a realização de uma pré-consulta e uma primeira escuta. Ou, se na hora da coleta para exames o usuário tivesse alguma dúvida e não fosse da área de abrangência do profissional que estava colhendo o exame, este solicitava o endereço ao usuá- 
rio, verificava no quadro qual equipe era responsável por sua área de abrangência, qual profissional poderia atendê-lo e aproveitava a oportunidade para informar as atividades da ESF na área de sua residência.

Em outra direção, a discriminação por cores garantiu a efetivação de outra diretriz do PSF: a responsabilização e o vínculo das equipes com a população adscrita. A partir dela não só os profissionais de saúde reconhecem mais facilmente "seus" usuários, como também o inverso é verdadeiro. Numa das passagens, presenciamos um momento em que uma usuária chegou à recepção e, quando solicitado seu endereço, a própria já se identifica: "sou da equipe azul".

Quando questionada sobre as razões de separar os prontuários, a coordenadora responde (abaixo) apontando também para outros desafios do SUS: o acesso e a humanização:

Pra a equipe identificar a população e a população, assim, ser reconhecida aqui dentro. Porque se a equipe ainda trabalha, e trabalha como todos outros, muito centrada no centro de saúde ainda e não na equipe de saúde da família e isso não é uma coisa que você não vai mudar em 1 ano em 2 anos, eu precisava arrumar recursos para que a população pudesse ser reconhecida e assim, dentro da unidade. [...] Oh que equipe, não tinha nada que identificasse, era um prontuário branco, nada de diferente. Aí, assim, então num trabalhou isso, porque você sempre trabalhou com a população geral, toda comum. Não tinha ainda descoberto, de repente era uma forma de identificar, identificando o prontuário por área e isso aproximaria as equipes. Eu também não sabia o quanto aproximaria as equipes da população só depois [...] (X., coordenadora da UBS)

Não, porque assim, a população começa reconhecer a equipe dela aqui dentro. Também telefona, eu quero falar com fulano, a fulana mandou falar com ela, porque ela já sabe. Melhora o acesso, porque o acesso é a pessoa ter a oportunidade de ela ter o problema resolvido. Ela consegue trazer, levar o problema e ser resolvido. (idem)

O fato dela chegar, dela saber e a B. [enfermeira] que já conheça a história dela, já sabe do problema dela e a B. [enfermeira] tá acompanhando, se eu for chegar e falar então tá 'tudo bem? Bom dia', esse meu bom dia eu acho que nesse caso não organiza, ela vai começar do zero, vai explicar tudo, eu não vou entender o contexto, eu vou tomar uma conduta que de repente não é adequada. Mas a B. [enfermeira], que tá acompanhando, que sabe toda a história, 'não, não' é só isso aqui que tenho que fazer, pronto. Resolvido. Aí é humanização, na minha opinião. (idem)

\section{Considerações finais}

A invenção de diferentes práticas e instrumentos encontrados no âmbito do PSF, que orientam outra forma de organizar o trabalho na unidade, resultou de ajustes propiciados pela mobilização cognitivo-afetivo-corporal, envolvendo uma inteligência específica, apontada por Dejours (2004) como "inteligência astuciosa”.

Percebemos a existência de um espaço público interno de discussão na unidade, principalmente nas reuniões de equipe e na mesa de almoço, constituindo o momento em que eram debatidos as ações, os problemas e os casos, em que todos os envolvidos na discussão sugeriam possibilidades de encaminhamento, criando as condições propícias à visibilidade dos ajustes e ao seu julgamento. Transformava-se, então, esta inteligência em sabedoria, gerando a dinâmica do reconhecimento, potencializando o trabalho como operador de saúde.

Essa sabedoria compunha o patrimônio daquele PSF, configurando uma forma muito específica de trabalhar. Acreditamos estar em curso o engendramento e o processamento do que a Clínica da Atividade denomina de gênero profissional ou gênero social do ofício, na medida em que observamos a construção de obrigações como, por exemplo, não permitir que nenhum usuário abandone a unidade sem ser escutado e as avaliações construídas pelos próprios profissionais de saúde da unidade, usadas na regulação de sua atividade. O gênero profissional se expressava nesta unidade pela constituição de um repertório de maneiras de agir, modos de iniciar e finalizar a atividade de trabalho no PSF a fim de garantir seus objetivos frente à ausência concreta do "como fazer o PSF", apontada pelos diferentes profissionais.

O estabelecimento de uma zona de desenvolvimento potencial, a construção deste gênero profissional na unidade ampliava a capacidade normativa dos profissionais de saúde envolvidos com o cuidado à saúde, sua ação sobre os meios de trabalho e sobre si mesmo. De modo que detectamos na "forma de fazer o PSF" naquela unidade o enlace entre a inventividade, a luta pela saúde e a eficácia de suas ações.

O reconhecimento da eficácia do PSF realizado na unidade pode ser relatado em diferentes direções. Nossa primeira sinalização foi a indicação, por uma docente da Universidade Estadual de Londrina, daquele PSF como uma experiência bem-sucedida. Por outro lado, durante o desenvolvimento da pesquisa, o espaço da unidade era compartilhado não só com os profissionais que lá trabalham, mas também com uma série de outros pesquisadores que chegavam à unidade com o mesmo propósito: investigar aquela experiência de PSF. Os percursos até chegarem àquela unidade foram diferenciados, mas nos chamou atenção o fato de a maioria ser encaminhada pela própria gerência municipal de saúde com a mesma indicação: experiência bem-sucedida.

Os espaços de discussão e o debate constante entre os diferentes trabalhadores sobre o desenvolvimento do trabalho no âmbito do PSF naquela unidade ofereciam oportunidade de retoques e de re-elaboração dos modos de agir pelos profissionais de saúde envolvidos, 
garantindo assim a renovação permanente do gênero profissional. A coordenadora da unidade explica:

Então, eu preciso ter essa visão, preciso estar conversando com os profissionais porque eles também, porque o que acontece quando você tem esse atendimento, esse tumulto, você não consegue raciocinar e esse, essa coisa de fazer, fazer, atender, e é urgência agora, corre, entra na outra sala, ausculta, isso é como se desse uma, como que eu vou dizer pra você, você fica meio robô, você não raciocina. (X., coordenadora da UBS)

Isso eu descobri que funciona, você construir um instrumento ali com aquela equipe, com aquela realidade. (idem)

\section{Referências}

BAKHTIN, M. A estética da criação verbal. São Paulo: Marins Fontes, 2000.

BRASIL. MINISTÉRIO DA SAÚDE. Programa Saúde da Família: ampliando a cobertura para consolidar a mudança do modelo de Atenção Básica. Rev. bras. Saúde Mater. Infant., v. 3, n. 1, p. 113-125, jan./mar., 2003.

- Avaliação normativa do Programa Saúde da Família no Brasil/ Monitoramento da implantação e funcionamento das equipes de Saúde da Família -2001/2002, Brasília, 2004.

. Atenção Básica e Saúde da Família. Números da Saúde da Família, 2007. Disponível em: http://dtr2004.saude.gov.br/dab/abnumeros. php\#numeros. Acesso em: 25 jul. 2007.

BRITO, J. et al. Saúde, cadê você? Cadê você? In: BRITO, J., NEVES, M.; ATHAYDE, M. (Orgs.). Caderno de textos: programa de formação em saúde, gênero e trabalho nas escolas. João Pessoa: Editora Universitária/UFPB, 2003. p. 23-40.

CAETANO, R.; DAIN, S. O Programa de Saúde da Família e a reestruturação da atenção básica à saúde nos grandes centros urbanos: velhos problemas, novos desafios. Physis, Rio de Janeiro, v. 12, n. 1, p. 11-21, 2002.

CAMPOS, G. W. S. A Saúde Pública e a Defesa da Vida. São Paulo: HUCITEC, 1991.

CANGUILHEM, G. O normal e o patológico. 5.ed. Rio de Janeiro: Forense Universitária, 2000.

. Meio e normas do homem no trabalho. Pro-posições, Campinas, v. 12, n. 2-3, p. 109-121, jul./ nov., 2001.

. A saúde: conceito vulgar e questão filosófica. In: Canguilhem G. Escritos sobre a Medicina. Rio de Janeiro: Forense Universitária, 2005, p. 35-48.

CAPONI, S. Georges Canguilhem y el estatuto epistemológico del concepto de salud. Hist. cienc.
Se entendemos que trabalhar não é mera execução de normas e prescrições, no caso do PSF acrescenta-se outro ingrediente: a ausência de instruções de como fazê-lo funcionar. Os profissionais de saúde, operadores do PSF junto com os usuários, frente ao "vazio de normas" gerado pelas lacunas da organização prescrita do trabalho, renormatizavam seu meio de trabalho, criando instrumentos, sistemas de informação e comunicação e procedimentos. Por outro lado, lembremos que renormatizar remete às dramáticas do uso de si, instaladas pela tentativa de articular o uso de si por/para outrem e o uso de si por/para si.

saude-Manguinhos, Rio de Janeiro, v. 4, n. 2, p. 287307, jul./out., 1997.

CLOT, Y. Le travail sans l'homme? Pour une psychologie des milieux de travail et de vie, Paris: La Découverte, 1995.

. A função psicológica do trabalho.

Petrópolis: Vozes, 2006.

Clinique du travail et clinique de l'activité. Nouvelle Revue de Psychosociologie n. 1, Paris, 2006a, p. 165-177.

Travail et pouvoir d'agir. Paris: PUF, 2008.

CONILL, E. M. Políticas de atenção primária e reformas sanitárias: discutindo a avaliação a partir da análise do Programa Saúde da Família em Florianópolis-SC, 1994-2000. Cad. saúde púb., Rio de Janeiro, v. 18, p. 191-202, 2002. Suplemento.

DAL PAI, D.; LAUTERT, L. Agentes comunitários de saúde: a busca pela confiança e reconhecimento. In: CREUTZBERG, M. et al. (Orgs.). CONGRESSO BRASILEIRO DE ENFERMAGEM, 56., 2004, Gramado. Livro-Temas. Gramado: 2004. Disponível em: http://bstorm.com.br/enfermagem. Acesso em: 26 set. 2005.

DEJOURS, C. Por um novo conceito de saúde. Rev. bras. Saúde ocup., São Paulo, v. 14, n. 54, abr./jun., 1986.

Por um trabalho, fator de equilíbrio. Rev. adm. emp., São Paulo, v. 33, n. 3, p. 98-104, 1993.

. O fator humano. Rio de Janeiro, Editora FGV, 1997.

. Inteligência prática e sabedoria prática: duas dimensões desconhecidas do trabalho real, In: LANCMAN, S.; SZNELWAR, L. (Orgs.). Christophe Dejours: da psicopatologia à psicodinâmica do trabalho. Rio de Janeiro/Brasília: Fiocruz/Paralelo 15, 2004. p. 277-299. 
Subjetividade, trabalho e ação. Revista

Produção, v. 14, n. 3, p. 27-34, set./dez, 2004.

GUÉRIN, F. et al. Compreender o trabalho para transformá-lo: a prática da ergonomia. São Paulo: Edgard Blücher, 2001.

MENDES GONÇALVES, R. Medicina e História: raízes sociais do trabalho médico. 1979. 203 f. Dissertação (Mestrado em Medicina) - Faculdade de Medicina, Universidade de São Paulo, São Paulo, 1979.

MERHY, E. Saúde: a cartografia do trabalho vivo. São Paulo: Hucitec, 2002.

ODDONE, I.; RE, A.; BRIANTI, G. Redécouvrir l'expérience ouvrière. Paris: Edicions Sociales, 1981.

PEDUZZI, M.; SCHRAIBER, L. Processo de trabalho em saúde. In: ESCOLA POLITÉCNICA DE SAÚDE (Org.). Dicionário da educação profissional em saúde. Rio de Janeiro: Fiocruz, 2006.

RIBEIRO, E. M.; PIRES, D.; BLANK, V. L. G. A teorização sobre processo de trabalho em saúde como instrumental para análise do trabalho no Programa Saúde da Família. Cad. saúde púb., Rio de Janeiro, v. 20, n. 2, p. 438-446, mar./abr. 2004.

SCHWARTZ, Y. Expérience et connaissance du travail. Paris: Messidor/Éditions Sociales, 1988.

Travail et Philosophie: convocations mutuelles. Toulouse: Octarès, 1992.

. Le padadigme ergologique ou un métier de Philosophe. Toulouse: Octarès, 2000.
Ergonomia, filosofia e exterritorialidade.

In: DANIELLOU, F. (Org.). A ergonomia em busca de seus princípios: debates epistemológicos. São Paulo: Edgard Blücher, 2004. p. 141-180.

SCHWARTZ, Y.; DERRIVE, L. (Orgs.). Trabalho e ergologia: conversas sobre a atividade humana. Niterói: EdUFF, 2007.

SILVA, A. C. B. A gestão de unidades básicas de saúde frente ao desafio da estratégia de saúde da família. 2006. 208 f. Dissertação (Mestrado em Psicologia Social) - Instituto de Psicologia, Universidade do Estado do Rio de Janeiro, Rio de Janeiro, 2006.

SOUZA, H. M.; SAMPAIO, L. F. Atenção Básica: política, diretrizes e modelos coetâneos no Brasil. In: NEGRI, B.; FARIA, R.; VIANA, A. L. A. (Orgs.). Recursos Humanos em Saúde: política, desenvolvimento e mercado de trabalho. Campinas, SP: Unicamp, IE, 2002. p. 9-32.

VIANA, A. L.; DAL POZ, M. A reforma do sistema de saúde no Brasil e o Programa de Saúde da Família. Physis, Rio de Janeiro, v. 8, n. 2, p. 11-48, 1998.

VIGOTSKI, L. S. A formação social da mente: o desenvolvimento dos processos psicológicos superiores. São Paulo: Martins Fontes, 2000.

ZARIFIAN, P. Mutação dos sistemas produtivos e competências profissionais: a produção industrial de serviço. In: SALERNO, M. (Org.). Relação de serviço: produção e avaliação. São Paulo: SENAC, 2001. p. 67-93. 